\title{
Conversas sobre sexualidade na família e gravidez na adolescência: a percepção dos pais
}

\author{
Ana Cristina Garcia Dias \\ William B. Gomes
}

Universidade Federal do Rio Grande do Sul

\begin{abstract}
Resumo
Estudou-se a percepção sobre dificuldades informativas e comunicativas em conversas sobre sexualidade com as filhas. Entrevistou-se quatro casais e cinco mães, envolvendo oito famílias com filhas adolescentes grávidas, pertencentes à classe média baixa. Na análise, seguiram-se os três passos reflexivos da Psicologia Fenomenológica: descrição, que indica o modo de compreensão do tema em foco; redução, que especifica criticamente o modo de compreensão e sua relação com a concretude da situação; e interpretação, que explora novas possibilidades para compreensão, explicação e intervenção. Interpretou-se que os pais encontravam-se confusos em relação aos valores relacionados à sexualidade das jovens e também em relação ao seu papel na educação sexual. A informação era ambígua desde que os pais não tinham clareza dos valores que pretendiam transmitir aos filhos. Por conseguinte, a comunicação não se estabelecia pela ambigüidade associada à re-significação da experiência sexual dos pais diante das vivências das filhas, e das transformações de valores da atualidade. Os pais percebiam adequadamente o que estava acontecendo com a vida sexual das filhas mas não conseguiam meios expressivos efetivos para orientação 1) por estimarem equivocadamente o conhecimento das filhas sobre anticoncepcionais; 2) por tentarem postergar a iniciação sexual das filhas; e 3) por não se considerarem aptos para falar de sexualidade e de métodos anticoncepcionais.
\end{abstract}

Palavras-chave: conversas, adolescência, família, gravidez, Fenomenologia 


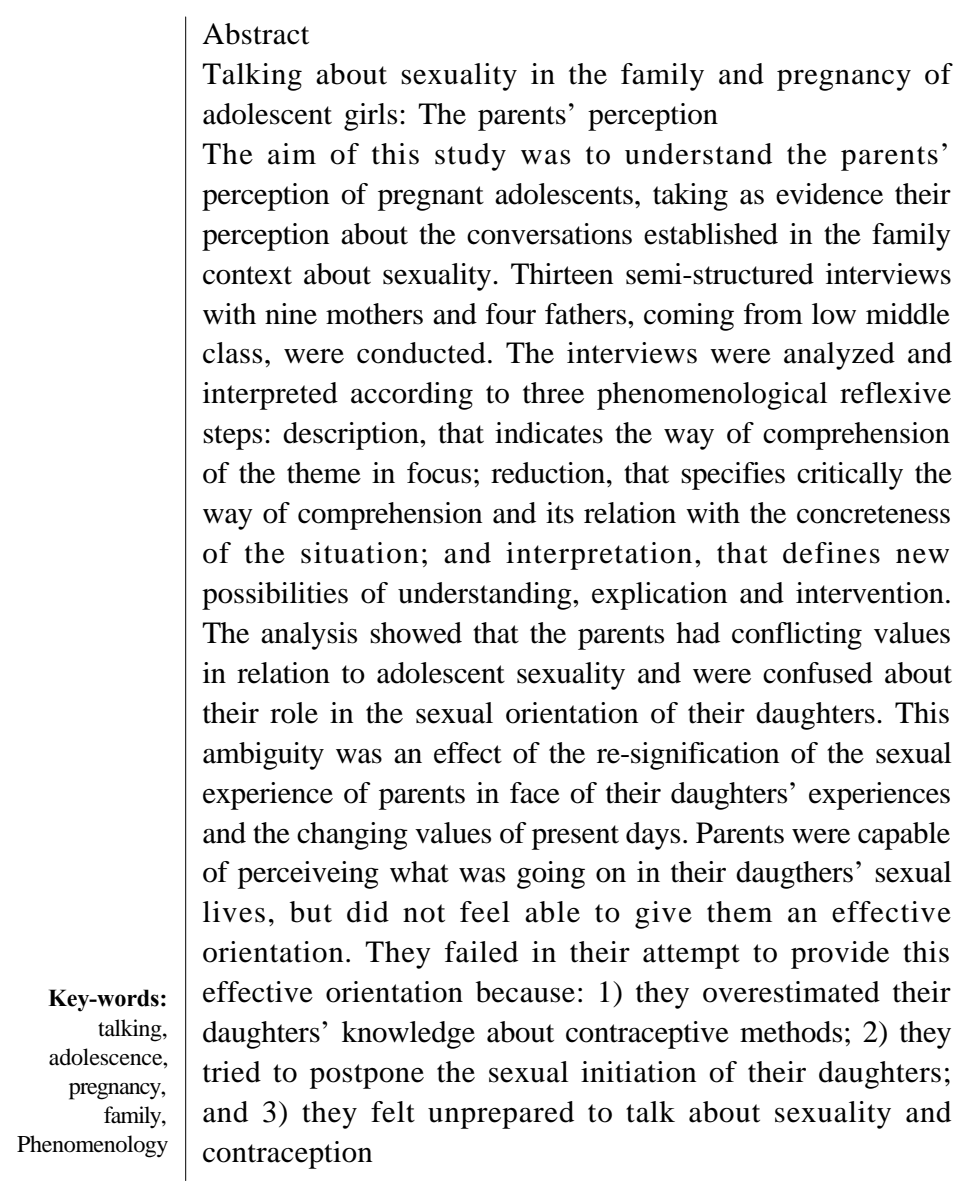

gravidez na adolescência representa um momento de crise
no ciclo de vida familiar. Para a adolescente, a gravidez
pode significar uma reformulação dos seus planos de vida e a necessidade de assumir o papel de mãe para o qual ainda não está preparada. Para os pais, tal experiência é marcada por sentimentos variados, tais como surpresa, decepção, raiva, culpa ou alegria, e 
também por questionamentos do tipo "por que isto aconteceu?", "onde foi que eu errei?", "será que dei liberdade demais à minha filha?". $\mathrm{Na}$ verdade, a gravidez na adolescência denuncia, de um modo contundente, um fenômeno que costuma ser ignorado no ambiente familiar - a sexualidade do adolescente. Por isso a gravidez, ao mesmo tempo em que exige novos arranjos na estrutura e funcionamento familiar, questiona os pais e a própria adolescente sobre os modos de percepção e expressão da sexualidade.

A gravidez da adolescente apresenta-se aos pais como uma nova experiência para a qual buscarão constituir um sentido. Um sentido que é tanto retrospectivo em relação às vivências sobre sexualidade no ambiente familiar antes da gestação, quanto prospectivo em relação às mudanças e novos arranjos que se processam a partir da gestação. Tal sentido constitui-se na maneira como os pais percebem e decodificam três conjuntos interdependentes de signos: a cultura, a família e a própria individualidade.

Os signos culturais referem-se às ideologias sobre sexualidade e família que circulam no meio em que vivem os pais. Incluem as percepções dos pais sobre suas condições concretas de existência (renda familiar, bairro onde moram, valores comuns) e as percepções sobre as mensagens veiculadas pela mídia sobre o comportamento habitual dos jovens. Estas percepções defrontam-se com contrastes e diferenças geracionais na linguagem, nas diversões preferidas e na moda. Os signos culturais também são influenciados pelas percepções da violência urbana e das doenças sexualmente transmissíveis.

Os signos familiares referem-se ao estilo de relação interpessoal e prática comunicativa entre os pais, entre os filhos, e entre os pais e os filhos. Como se sabe, a estrutura familiar passou por muitas transformações nos últimos anos. A família trocou o modelo hierárquico, no qual os papéis familiares eram rigidamente estabelecidos e o poder centralizado na figura do pai, por um modelo igualitário, no qual se destacam os ideais de liberdade e respeito à individualidade. Neste modelo, não é correto que os pais imponham suas idéias aos filhos ou os proíbam de fazer certas coisas. O desenvolvimento dos filhos passa a ser orientado pela experimentação e descoberta. $\mathrm{O}$ 
diálogo, e não a autoridade, impõe-se como valor fundamental na educação e nas relações familiares (Benincá, 1994; Figueira, 1991).

Por fim, os signos individuais sintetizam os sentimentos e questionamentos do pai e da mãe sobre os comportamentos, problemas e promessas dos filhos em relação ao futuro. São percepções influenciadas pela formação educacional, atividades profissionais, relações sociais, características de personalidade e estilos cognitivos de cada um, seja o pai, seja a mãe. Os signos individuais não podem ser considerados nem compreendidos isolados do mundo que os cercam. Ademais, possuem o poder de, como percepção de si e do mundo, expressar-se como mediador, facilitador ou complicador dos problemas inerentes ao próprio curso da vida familiar (Wiley, 1994/ 1996). Convém notar que os três conjuntos de signos descritos incluem as formações perceptivas e expressivas tanto dos pais quanto dos filhos, enquanto partes de um elo comunicativo (Gomes, 1997).

É compreensível que, neste delicado e complexo contexto semiótico, isto é, formado por sistemas interligados de signos e códigos, pais e filhos encontrem dificuldades em iniciarem conversas sobre sexualidade. Os jovens sentem-se constrangidos ou temem a desaprovação de seus pais. Os pais, por sua vez, sentem-se despreparados e desajeitados para abordar o assunto (Liskin, Kak, Rutledge, Smit \& Stewart, 1987). De fato, conversar sobre sexualidade é muito mais do que simplesmente transmitir informações. Requer a transposição de barreiras, como idade e valores, em favor de uma proximidade que facilite a percepção do momento existencial do filho, mediada por mensagens que não sejam nem restritivas e nem permissivas. Implica a formação de uma aliança comunicativa na qual filho ou filha encontre espaço e apoio para o desenvolvimento psicológico. Contudo, muitos pais e filhos não conseguem estabelecer essa condição existencial para o diálogo, principalmente quando o tema é sexualidade. Os pais, quando conseguem abordar o tema, não encontram meios de desvencilhar-se de suas histórias pessoais, às vezes conflituadas, e limitam-se a oferecer ou impor conselhos superficiais (Fleury, 1995).

A comunicação sobre sexualidade entre pais e filhos é marcada, enfim, por uma ambigüidade em que ambas as partes reconhecem o problema, mas evitam enfrentá-lo. O dilema está então constituído. 
A ambigüidade explicita-se na percepção problemática dos desdobramentos prováveis da comunicação. Por exemplo, a orientação sexual poderia levar a iniciação sexual precoce? Ou a falta de orientação poderia resultar em doenças ou gravidez indesejada?

Sabe-se que a gestação na adolescência pode tanto decorrer da ausência de informação (Agostini, Luz, Santos \& Mendes, 1988; Bueno, Neme, Neme, Aldrighi, Cassiani \& Vera, 1996; Maia Filho, Mathias, Tedesco, Cesareo, Herculano \& Porta, 1994; Monteiro \& Cunha,1994), quanto de erros no uso de métodos contraceptivos (Dias, Oliveira \& Gomes, 1997; Rodrigues, Souza, Brasil \& Carakushansky, 1993; Silva, Sarmento, Lander \& Faundes,1980). Autores vinculados à tradição psicanalista (Blos, 1962/1994; Marcelli \& Braconnier, 1989) argumentam que prática sexual na adolescência e a possível gravidez expressam motivações inconscientes de separação dos pais e de antecipação de vida adulta. Autores atentos ao desenvolvimento cognitivo (Barnett, Papini, \& Gbur, 1991) apontam, por sua vez, para relações importantes entre déficits intelectuais e gravidez na adolescência. De qualquer modo, a implementação de um comportamento contraceptivo eficaz está estritamente relacionada ao contexto em que as informações sobre sexualidade são transmitidas e significadas. É neste contexto compartilhado por pais e filhos que percepção e expressão podem ser prejudicadas por dificuldades cognitivas, lapsos inconscientes, carências afetivas, problemas de relacionamentos interpessoais.

Este estudo focaliza a percepção de mães e pais das conversas sobre sexualidade com filhas adolescentes. O estudo preocupa-se com os códigos de comunicação familiar sobre sexualidade e contracepção e suas possíveis relações diacrônicas (determinantes históricos) e sincrônicos (determinantes contextuais) na gestação da adolescência.

\section{Método}

\section{Informantes}

Participaram como informantes deste estudo oito mães e quatro pais de adolescentes grávidas, envolvendo nove famílias (ver sumário no Apêndice A). As famílias foram localizadas através das filhas 
que participavam de um programa de acompanhamento pré-natal no Hospital de Clínicas de Porto Alegre.

\section{Instrumento e Procedimentos}

Foi utilizado um roteiro tópico para entrevista constituído de 16 itens baseado na literatura revisada e na experiência dos pesquisadores (Apêndice B). A entrevista tinha como objetivo reconstituir um conjunto amplo de circunstâncias comunicativo-familiares que caracterizassem a gravidez da adolescente. O primeiro contato com os possíveis informantes foi realizado através de telefone, carta ou pessoalmente na consulta de acompanhamento pré-natal da filha, no Hospital de Clínicas de Porto Alegre. Inicialmente, eram explicados às mães ou aos pais os objetivos do estudo e de que modo eles poderiam participar. Caso concordassem em participar da pesquisa, era marcada uma data e local. No início da entrevista, após nova apresentação e esclarecimentos sobre os objetivos do trabalho, era entregue aos pais um termo de consentimento pós-informação, conforme aprovação do Comitê de Ética do Hospital de Clínicas de Porto Alegre. As entrevistas foram realizadas em diferentes locais, tais como, corredor do hospital, sala do serviço de Psicologia e residência dos entrevistados. Alguns pais preferiram ser entrevistados ou começaram a participar da entrevista quando as mães estavam sendo entrevistadas. Observou-se que os pais sentiam-se mais à vontade para falar em companhia das mães. De maneira geral, as mães foram mais receptivas à proposta de pesquisa. Na verdade, poucas intervenções foram necessárias para obter as informações indicadas no roteiro tópico da entrevista pois as mães abordavam espontaneamente os itens do roteiro. As entrevistas variaram entre uma a duas horas e meia de duração.

\section{Resultados}

Os depoimentos obtidos através das entrevistas foram analisados e sintetizados através de três passos sistêmicos e sistemáticos baseados na fenomenologia existencial (Giorgi, 1975; Merleau-Ponty, 1945/1994) e na fenomenologia semiótica (Gomes, 1997; Lanigan, 1988), denominados de descrição, redução e interpretação fenomeno- 
lógica. Os passos indicados serviram tanto para orientar os procedimentos de descrição qualitativa quanto os procedimentos de análise e crítica. A regra básica na condução da análise foi a suspensão do julgamento dos pesquisadores quanto aos valores apresentados pelos entrevistados em seus depoimentos. No entanto, preservou-se o julgamento crítico em relação à clareza e abrangência da síntese descritiva. Para tanto, recorreu-se aos procedimentos sistemáticos de identificação exaustiva de micro e macro unidades de significado para garantir o rigor das leituras e sínteses. Procedeu-se, ainda, à demarcação de frases chaves oferecidas pelos entrevistados que foram julgadas pelos pesquisadores como sínteses esclarecedoras do que estava sendo dito (Giorgi, 1975; Gomes, 1987; Gomes, 1998 e Lanigan, 1992).

A abrangência da entrevista e a grande disposição das mães em historiar o ocorrido trouxe um grande volume de dados sobre o episódio da gravidez da filha. No entanto, este estudo focalizará dois temas: 1) conversas e vivências sobre sexualidade no contexto familiar de origem das mães e dos pais; e 2) conversas e vivências sobre sexualidade na relação entre pais e filhas adolescentes.

A análise qualitativa fenomenológica apresentada a seguir está organizada nos três passos previamente indicados. O primeiro passo, ou descrição fenomenológica traz uma síntese geral e não crítica dos temas indicados, baseada no material empírico recolhido na entrevista. O segundo passo, ou redução fenomenológica, é um retorno à descrição para questioná-la, especificando suas partes temáticas, diferenciando a força constitutiva de cada parte (relevante do irrelevante; essencial do complementar), para escolher que parte aprofundar. Uma vez escolhida uma determinada parte, retornou-se às entrevistas e aos protocolos para localizar novos subsídios que confirmassem, ou não, a relevância da parte escolhida. A exposição da redução compõe-se de excertos das entrevistas para servirem de evidência ao argumento apresentado. Por fim, o terceiro passo, ou interpretação fenomenológica, é um balanço crítico entre o que foi descrito e o que foi especificado ou reduzido. Nesta etapa final os pesquisadores confrontam os próprios julgamentos com os julgamentos ou sentidos identificados na descrição como pertencentes aos 
entrevistados. A interpretação caracteriza-se como indicação de possibilidades de ocorrências associadas ao fenômeno em estudo e não como generalização de achados.

Tema Um: Conversas e vivências sobre sexualidade no contexto familiar das mães e dos pais.

\section{Descrição Fenomenológica}

$\mathrm{O}$ contexto em que se estabelecem as conversas entre pais e filhos sobre sexualidade é, em parte, constituído por recordações da vivência familiar dos tempos de juventude. Em suas lembranças, a descoberta e desenvolvimento da sexualidade ocorreu em um ambiente repressor, preconceituoso e obscuro. A família era a principal reguladora da sexualidade e as orientações eram indicações de proibições. As informações recebidas limitavam-se à explicação de regras de conduta e estavam apoiadas em valores que priorizavam a manutenção do sistema familiar. Esses pais não percebiam suas famílias de origem como disponíveis para oferecer informações sobre sexualidade. As informações eram obtidas através de revistas, amigas e colegas de escola, longe dos olhos dos pais. A oportunidade de um diálogo aberto sobre sexualidade era escassa. O problema não estava restrito a disponibilidade de informações. Havia dificuldades com determinados recursos de higiene e prevenção (referindo-se a absorventes e a "camisinha"), e o conhecimento sobre métodos contraceptivos era ainda precário. A sexualidade e as formas de prevenção não eram debatidos pela mídia, pois não existia o medo da violência e nem da AIDS. Aliás, os pais consideraram esses dois fenômenos como fatores contemporâneos importantes, que os levaram à procura do diálogo com os filhos sobre sexualidade e contraceptivos.

A utilização de métodos contraceptivos, na adolescência, pelos informantes, foi prejudicada por causa da desinformação, de valores religiosos ou até mesmo de planos futuros para ter filhos. Temia-se que determinados métodos pudessem prejudicar a fertilidade. As práticas sexuais consideradas seguras envolviam a masturbação a dois, o coito interrompido e o "método da lua". Note-se, contudo, 
que algumas das famílias entrevistadas foram constituídas a partir de gestações na adolescência. Os relatos mostram também que esses pais se identificaram com as filhas no que se refere a alguns valores e práticas relacionados à sexualidade. Por exemplo, houve referências a um não aproveitamento da adolescência por razões de gravidez e conseqüente responsabilidade com casa e filhos.

\section{Redução fenomenológica}

A descrição nos ofereceu um panorama amplo do contexto em que os pais tomaram contato com as questões da sexualidade. Cabe à redução ampliar partes desse contexto para clarificar as regras que delimitaram a comunicação e as vivências relacionadas à sexualidade na experiência dos pais. Assim, a tarefa da redução será esclarecer determinadas partes do contexto repressivo apresentado na descrição, tais como: 1) pais repressores; 2) obediência por respeito aos pais; 3) regra diferenciada para meninos e meninas; 4) orientação como impedimento; e 5) re-situacionamento dos pais frente à realidade atual. A análise das partes mencionadas toma como ponto de partida a fala dos pais, tomando um exemplo para cada tema.

1) Pais repressores

Marta: "A minha mãe não deixava nem sequer a gente ler revistas. $\mathrm{Na}$ época havia muitas revistas em quadrinhos, e já vinha algumas revistas tipo Realidade ... Cruzeiro não vinha, continuava a mesma de sempre ... Começaram a dar as primeiras entradas assim, me lembro que ela proibiu a entrada da Seleções dentro de casa porque ali dizia como é que a gente explicava pra criança como que o neném é gerado, aquelas coisas assim. Então era a partir dessas coisas que eu sabia. Aparentemente eu sabia tudo, mas porque eu lia. Porque eu tava sempre procurando... e conversava com as colegas da escola, a gente tava, sempre conversava sobre tudo".

Estela: "Eu fiquei sabendo de... assim depois que eu ... com leituras. Eu procurava ler revistas. Eu tinha um tabu assim que aquilo era pecado, tomar anticoncepcional era pecado. Evitar filho era pecado. (...) Mas não me explicou cientificamente o que era (a menstruação). Isso eu descobri depois com leituras. Aí me aguçou a curiosidade, 'eu tenho que saber o que é isso, porque que é'. Aí eu fui procurar em revistas, daí eu descobri o que era anticoncepcional, o que era gravidez, o que era... que eu tinha 13,14 anos eu não sabia 
como é que ficava grávida. Eu achava que engravidava com o beijo. Até achava assim que namorado, se tivesse assim muito próximo assim, poderia engravidar de tá muito próximo".

2) Obediência por respeito aos pais

Surla: "Então eu sempre dizia pra ele, eu quero me casar, de véu e grinalda, não tanto por mim, mas pela minha mãe. Eu tenho que ter consideração com a minha mãe porque ela fez muito sacrifício pra criar nós. E eu, porque eu vou dar essa decepção pra ela? (...) Então eu disse, eu vim sozinha pra Porto Alegre, e eu não tinha... Então, mas eu sempre de qualquer coisa eu pensava na minha mãe, coisa que hoje não acontece. Hoje eu acho que eles não pensam, tu faz tudo, sabe, tu faz e tu faz e tu faz. E eu acho que os filhos eles não pensam muito no pai e na mãe".

3) Regra diferenciada para meninos e meninas

Jerson: "(Sobre os conselhos que o pai lhe oferecia) Pra gente só nos cuidarmos com quem. Com quem e aonde. Pra evitar a filha de alguém, tinha aquelas famílias tradicionais. Pra evitar choque entre famílias. Então procurava fazer distante daquela parte familiar, distante dos laços familiares".

As falas transcritas mostram que as regras norteadoras da sexualidade eram de restrição à informação e ao comportamento sexual. $\mathrm{O}$ respeito à família, especialmente em relação à figura dos pais, era um valor subjacente ao estabelecimento das regras sobre a sexualidade. Por exemplo, Jerson nos aponta que a regra por ele recebida se constituía em não transar com moças de família. O caráter proibitivo da sexualidade também refletia-se nos métodos contraceptivos utilizados. O coito interrompido, o "método da lua" ou mesmo a masturbação eram formas contraceptivas que interrompiam o curso de uma relação sexual ou a impediam em determinados períodos. Em um contexto em que as regras estabelecidas fundamentavam-se na negação do comportamento sexual não são surpreendentes as queixas de desinformação.

A comunicação sobre sexualidade e contracepção nessa geração ocorreu predominantemente no grupo de pares. Com os amigos partilhavam-se experiências e esclareciam-se dúvidas. Nesse sentido, as 
publicações sobre temas relacionados à sexualidade em revistas tiveram um papel fundamental. Elas ofereceram alguns subsídios para conversas sobre sexualidade e contracepção nos grupos de pares.

Os pais ressaltaram que, com exceção dos riscos decorrentes da AIDS e da maior violência urbana, os parâmetros atuais da sexualidade das filhas são positivos. Os exemplos citados foram a abertura à experimentação, mais liberdade e ousadia, e maior conhecimento e informação. $\mathrm{Na}$ verdade, percebe-se que esses pais se identificam com as jovens. Eles muitas vezes colocam-se no lugar das adolescentes para avaliarem a experiência sexual das meninas como ilustra o excerto seguinte.

Salete: "Menos que eu avisei. Porque eu quando eu dizia prá Karine [a filha] 'eu não quero que tu faça isso', é por causa disso, disso e aquilo. Como eu disse pra ela: 'Eu não quero que tu vá lá pro Márcio, porque eu não quero que tu fique sozinha com o Márcio. Porque se tu ficar sozinha com ele, vai te dar uma vontade de vocês se agarrarem, se beijarem'. (...) E na minha época não, na minha época, se eu queria ir, como eu contei pra mãe. A mãe não deixava eu ir. (...) Não explicava nada, só não deixava. E aí, tinha às vezes esses sonsos perto de casa, a mãe não dizia: 'Tu vai ali, aqui é uma vila e pode dar até um tiroteio'. A mãe não explicava isso: 'Não, tu não vai, não vai, não vai'. E aí eu ficava braba, eu ficava revoltada. Por que que eu não podia ir?"

\section{Interpretação fenomenológica}

A redução ampliou o contexto, cabe agora à interpretação especificar as regras que dão significado às experiências desses pais. Como vimos, a percepção da sexualidade desses pais é redimensionada a partir da perspectiva dos filhos. O contexto intrapessoal de sua experiência é agora re-significado na esfera interpessoal, que envolve a relação entre os pais e suas filhas, bem como as influências do mundo circundante mais amplo (novos valores na cultura no que se refere à sexualidade, AIDS, violência). É a alteridade que se estabelece entre a experiência dos pais e a de suas filhas (que inclui os novos valores) que possibilita a re-significação da sexualidade dos pais. A regra decorrente desse novo enquadre dado à sexualidade é a imple- 
mentação obrigatória de um diálogo sobre a temática no contexto familiar, diferentemente do que foi experienciado em suas adolescências.

Como vimos, a comunicação estabelecida no ambiente familiar desses pais era repressora, predominando regras proibitivas. Atualmente, a regra que orienta a ação é afirmativa. Os pais estão buscando implementar um diálogo sobre sexualidade, tentando oferecer a eles informações às quais não tiveram acesso. Contudo, apesar da expressão da regra se constituir em uma afirmação (conversar com os filhos) a estrutura lógica subjacente continua a ser proibitiva (não repetir sua experiência) e impositivo (obrigatoriedade do diálogo).

Diversos estudos (Almeida, 1987; Benincá, 1994; Nicolaci-DaCosta, 1988) descreveram mudanças nas práticas educativas em conjunção com transformações sociais e familiares. Houve uma valorização progressiva da flexibilidade e permissividade nas regras cotidianas, além do incentivo à autonomia e às demonstrações de afeto nas relações familiares. Benincá (1994) ressaltou que as regras de socialização assumiram essa mesma direção. As estratégias impositivas baseadas na clara separação de papéis hierárquicos dentro sistema familiar foram gradualmente sendo transformadas em práticas comunicativas mais igualitárias, apoiadas no afrouxamento das relações de poder anteriormente estabelecidas. Atualmente, essas práticas educativas ganham sua expressão máxima na idéia da "experimentação", que reflete concepções mais centradas nos valores individuais. Nas palavras da autora, "a tática de socialização do 'obrigar', foi se transformando na socialização do 'conversar' para chegar, hoje em dia, na socialização do 'experimentar'” (Benincá, 1994, p. 87). As falas dos pais de nosso estudo, especialmente as mães, revelam que essas concepções perpassam suas práticas educativas no que se refere à orientação sexual das filhas. Esses pais valorizam o diálogo, a liberdade individual e a experimentação presentes na experiência das filhas.

Contudo, as mudanças nas famílias e na sociedade não obedecem a nenhuma sincronia. Algumas famílias, nos diferentes segmentos econômicos, antecipam mudanças enquanto outros as assimilam lentamente. Assim, a substituição de valores, embora lenta e 
gradual, pode ser sentida como súbita, deixando as famílias sem um referencial valorativo (Nicolaci-da-Costa, 1988). É neste sentido que se interpreta que os pais vivenciam a coexistência de um duplo padrão para a avaliação e orientação da sexualidade das filhas. O modelo de orientação recebido em suas famílias de origem era claro e explícito, inclusive sobre a sexualidade. Atualmente, as regras e comportamentos a serem transmitidos aos filhos não são claros. Como orientar um filho sem desrespeitar sua individualidade? O resultado desta confusão de valores é a ausência de um modelo de comportamento sexual ao qual os adolescentes possam se referir. Esses pais compreendem que não devem repetir o modelo de orientação sexual recebido em suas famílias, mas o único modelo conhecido (isto é, aprendido) é o da imposição de padrões. Neste contexto nebuloso, como surgem e desenrolam-se as conversas sobre sexualidade entre pais e filhas? É o tema da análise seguinte.

Segundo Tema: Conversas e vivências sobre sexualidade no ambiente familiar - A experiência das adolescentes

\section{Descrição Fenomenológica}

As conversas sobre sexualidade entre pais e filhas transitavam entre maior ou menor tolerância e restrição, dependendo da qualidade relacional, idade e tema abordado. A conversa assumia um caracter restritivo quando os pais tentavam orientar as filhas sobre os riscos associados à prática sexual tais como gravidez, doenças sexualmente transmissíveis, violência urbana, ou mesmo o risco de comprometer a imagem de uma "moça de família". Nessa forma de diálogo, além das proibições quanto à vivência da sexualidade, eram apontadas formas de comportamento que os pais julgavam como sendo mais adequados. Já no segundo tipo de conversa, menos restritivo (ou mais aberto), havia uma maior troca de experiências entre pais e filhas. Os pais buscavam entender como as filhas estavam vivendo a sua sexualidade, procurando criar um clima de confidencialidade. Neste estilo de conversa aberta, os pais percebiam-se mais próximos e igualitários às filhas e assim distantes de uma relação hierárquica tradicional. 


\section{A. C. G. Dias e W. B. Gomes}

\section{Redução Fenomenológica}

A descrição apresentou o contexto geral, ou pano de fundo, das percepções que os pais têm da forma como são vivenciadas as conversas sobre sexualidade no ambiente familiar. A redução vai focalizar os conteúdos dessas conversas e as dificuldades que pareciam prejudicar o diálogo. A pergunta que orienta a redução é "o que falam os pais com suas filhas sobre sexualidade e em qual contexto"? Os seguintes excertos ilustram algumas possibilidades:

Janete: "Eu dizia pra ela que ela não devia de fazer nada antes de casar, que devia se guardar, que podia acontecer do caso de uma gravidez, essas coisas assim".

Elisa: "Transar, ter um relacionamento, tu tem que ter consciência da onde, com quem e porque e pra que tu tá fazendo. Num lugar adequado, com uma pessoa que tu ame e que te ame também. Ou que tenha muita afinidade, com os devidos cuidados. Então essas eram as colocações que a gente tinha. E isso era colocado assim, na mesa do jantar, na mesa do almoço, então era muito aberto".

Salete: “...eu não disse pra ela: 'Ah não, mas tu usa'. Eu não cheguei a dizer pra ela: 'Tu usa camisinha'. Porque é uma coisa assim, se eu disser pra ela: 'Tu usa'. 'Ah, a mãe tá induzindo a fazer'. 'Tá, já sei, vamos usar camisinha'. Mas como a intenção não era que nem que ela fizesse isso, então eu não disse: 'Tu usa camisinha'. Eu disse: 'A camisinha ela evita filho, ela evita doenças venéreas'. (...) Então tudo isso eu explicava".

Os trechos destacados exemplificam três tipos de mensagens presentes nas conversas que os pais estabelecem com suas filhas: mensagens que enfatizam o perigo de uma relação sexual e sugerem que o sexo seja preservado para o casamento; mensagens que enfatizam a importância da qualidade do relacionamento e dos cuidados necessários para uma vida sexual segura; e mensagens que se confundem na ambigüidade entre querer orientar mas temer incentivar a prática sexual. No entanto, nenhuma das mensagens atingiu o objetivo de evitar as conseqüências de uma iniciação sexual na adolescência. Pergunta-se, então, por que falharam as mensagens que as mães (principalmente) passaram para suas filhas? As falhas seriam decorren- 
tes de dificuldades informativas, de dificuldades comunicativas, ou de falha generalizada na informação e na comunicação?

A descrição indicou que os pais orientavam-se por conhecimentos ou crenças que julgavam adequadas para as filhas. Mas quais eram esses conhecimentos ou crenças? Está aí uma parte da descrição que pode ser escolhida para uma discussão atenta. Os relatos permitem entender que o conhecimento sobre orientação sexual era limitado ou mesmo ausente nas mães e pais entrevistados. Por exemplo, eles acabavam passando às adolescentes uma idéia equivocada sobre anticoncepcionais ("Eu digo sempre prá elas, camisinha é só prá evitar doenças"). Contudo, não é apenas a falta de informação que afetava a comunicação. O tema da sexualidade parecia evocar sentimentos ambivalentes e um certo constrangimento de conversar abertamente com a filha.

Marisa:"(As conversas) são muito superficiais também. Às vezes eu fico me recriminando por que eu sou assim. Eu sou uma pessoa que trabalho com adolescente, dou aula. Às vezes eu consigo falar mais abertamente com um aluno do que com os meus filhos. Agora, ultimamente quem tem me questionado muito é o meu filho de 11 anos. E eu às vezes fico até atrapalhada pra responder certas coisas pra ele, quando ele vê a TV. (...) Com a Camila que é a mais nova, eu tenho procurado ... conversar melhor mas ainda não consegui. Eu só digo pra ela, ela tem namoradinho, às vezes eles começam a namorar e ficam: 'Olha eu não quero saber desse namoro no quarto de porta fechada', falo brincando mas preocupada".

A ambivalência dos pais sustenta-se em um conjunto de crenças que regulam as conversas com as filhas. São exemplos:

A crença de que as filhas já estariam suficientemente informadas.

Renato: "Várias vezes eu perguntei porque isso aconteceu, vocês não tiveram nenhuma orientação, a tua mãe nunca orientou?"

Salete: “...Então quer dizer, pelo que ela teve assim [na escola], ela deve ter visto o aparelho genital todinho, eu digo aí ela deve saber. De repente o erro foi meu de não ter explicado".

Estela: "Por isso eu acho que ela sabia muito mais do que eu pensava". Felícia: "Quando a gente vai conversar sobre esses assuntos assim, elas já tão sabendo antes, antes da gente falar elas já sabem, através 
94 A. C. G. Dias e W. B. Gomes

de amigas, através de... acho que o outro... não sei, mas eu sei que sabem".

A crença de que as filhas ainda são muito jovens para manterem relações sexuais.

Salete: "De repente, como eu te disse, ela me pegou assim muito de surpresa, que tinha coisa que eu queria explicar melhor pra ela. Mas eu pensava assim, um dia chegar pra ela e dizer: 'Ah minha filha, tu usa camisinha, tu pra se prevenir assim'. Como eu te disse, lá pelos 18, 19 anos".

Lúcio: "Isso aí é difícil a gente dizer, a idade pra começar é a idade tal, acho difícil dizer isso. Mas com certeza com 13 anos não é a idade pra começar a transar. É a idade de namorar, de dar uns amassinhos mais fortes, mas transar, não. Não é legal. Não tem uma idade, mas com certeza 13 anos não é a idade de isso acontecer".

Pressionados pela crença de que é necessário conversar sobre sexualidade com as filhas, os pais limitam-se a informar e não se preocupam com o modo como as filhas estão decodificando a informação. O caso de Janete, exposto a seguir, exemplifica a mediação dos valores dos pais na decodificação do contexto sexual em que vivem as filhas. Note-se, em especial, a dicotomia que se estabelece entre a percepção da sexualidade dos jovens em geral e a sexualidade das próprias filhas.

Janete: "Até aí ela não fazia nada mesmo, eu sei com certeza que ela não fazia. Ela queria me dizer e eu sempre dizia que eu não aceitava isso. Mesmo com toda essa juventude fazendo e acontecendo. Eu sei lá. Eu achava que a minha não devia de fazer. As outras eu não acho errado até, assim, sabe. Não é no da gente. Não que eu ache certo, mas não toca na gente, então não... Na minha eu não queria que acontecesse, eu sempre vinha dizendo pra ela: 'Não deixa, te cuida"”.

A fala de Janete traz uma expressão reveladora (e significante) da condição existencial que regula a aceitação, ou não, da sexualidade adolescente: "Não é no da gente". Quando "não é no da gente" parece mais fácil até mesmo conversar sobre sexo, como indicou Marisa em uma fala citada anteriormente, na qual reconhecia sentirse mais à vontade para conversar com os alunos do que com seus filhos. O que está implícito nessa atitude dos pais é, na verdade, a dificuldade em aceitar a sexualidade de suas filhas, e talvez a sua própria sexualidade. 
A situação experiencial de ter uma filha adolescente que começa a descobrir e viver sua sexualidade parece ser perturbadora para os pais. Os pais podem sentir-se culpados por não terem conversado com as filhas ("de repente o erro foi meu de não ter explicado"), ou recriminarem-se pelas dificuldades em abordar o temas. Podem, ainda, buscar isentar-se de culpa ressaltando que haviam informado as jovens sobre os riscos da atividade sexual, ou então que estiveram sempre dispostos a isso.

Surla: "A gente sempre deu liberdade. Não foi, olha se dependesse de falar nenhuma fazia nada errado, porque eu sempre estou falando...".

A diferença de valores entre pais e filhas também é percebida como um fator que torna difícil o estabelecimento de um diálogo dentro da família:

Renato: "Às vezes é difícil hoje sentar e conversar com um filho, explicar tudo o que é certo e errado na vida. Até da experiência, desse currículo que a gente tem de bagagem, desses anos todos que a gente passou. E passar pra ele essa experiência. Então é difícil, porque eles acatar não vão. Isso sim mudou com a época. Antigamente acatava mais, um conselho de um pai, de uma mãe, hoje não. Mesmo o pai sendo mais flexível, mais democrático. Sentar e conversar é mais difícil, não escuta. Ou se escuta, entra por um ouvido e sai pelo outro".

Percebe-se, na postura desse pai, a idéia de que o seu papel é "passar a experiência" para os filhos, embora reconheça que tal modelo de diálogo não seja muito efetivo. A ineficiência do diálogo familiar sobre sexualidade parece só se tornar consciente após um evento como a gravidez de uma filha:

Lúcio: "Eu acho que a gente tem que conversar, mesmo eu conversava, ou achava que conversava".

\section{Interpretação Fenomenológica}

A gestação da filha adolescente leva os pais a questionarem a qualidade das conversas sobre sexualidade. De uma forma ou de outra, 
os pais consideram que falharam nas orientações fornecidas às filhas. Na verdade, percebeu-se, especialmente na fala das mães, uma mescla de sentimentos de culpa e raiva quando avaliaram suas conversas com as filhas. Por um lado, as mães sentiam a necessidade de enfatizar que ofereceram informações sobre formas de prevenção às filhas. Por outro, sentiam-se culpadas por reconhecerem suas dificuldades pessoais em abordar o assunto. Na expressão dos pais, percebia-se um certo questionamento, mas o sentimento de culpa ou fracasso não se mostrava tão acentuado como ocorreu nas mães. Talvez porque a tarefa de conversar sobre sexualidade e prevenção com as filhas continuava sendo considerada uma função feminina, embora alguns pais também compartilhassem essa responsabilidade para si. Ou quem sabe, porque os pais seriam menos transparentes quanto à expressão dos seus sentimentos.

Zagury (1991) já observara que, diante das inúmeras teorias psicológicas e educacionais atuais, os pais sentem-se atemorizados frente à possibilidade de falhar na educação dos filhos. Os pais estão experienciando uma fase de transição na qual, ao mesmo tempo em que possuem consciência do que não devem fazer, não encontraram ainda um padrão adequado de comportamento em relação aos filhos. Ou seja, a transformação dos valores parentais não possibilitou, ainda, a implementação de um diálogo eficiente na relação pais/filhos no que se refere à sexualidade.

A redução nos mostrou que alguns pais percebem adequadamente o que está acontecendo com suas filhas em termos de experiências sexuais, conseguindo identificar quando as filhas desejam conversar sobre sua sexualidade ou quando estão prestes a iniciar sua vida sexual. Contudo, a não aceitação da sexualidade da jovem impedia a implementação de um diálogo eficiente sobre métodos contraceptivos. Além disso, a mesma sensibilidade perceptiva não foi observada em relação às informações que as filhas possuíam sobre sexualidade e contracepção. Alguns pais supunham que as filhas encontravam-se melhor informadas do que realmente estavam. Pensavam, inclusive, que as jovens tinham melhores informações que eles próprios sobre o assunto, o que sugere uma possível inversão no fluxo da informação dentro do sistema familiar para assuntos como 
a sexualidade (como pôde ser observado no caso de uma mãe que lia as revistas da filha - direcionadas ao público adolescente - para se manter atualizada sobre o assunto). Tal fenômeno, ressalte-se, ocorre em diversas áreas de conhecimento, uma vez que as transformações tecnológicas têm produzido novos saberes e informações que são melhor dominados pelos mais jovens, fazendo com que, de certa forma, os adolescentes atualmente tenham algo a ensinar a seus pais (Fisher, 1996).

A qualidade da informação transmitida foi precária. Como os pais supunham que as filhas possuíam um conhecimento satisfatório sobre sexualidade e métodos contraceptivos, limitavam-se a dar conselhos e a determinar proibições. Pouca informação sobre formas efetivas de prevenção eram oferecidas nas conversas sobre sexualidade. Na verdade, as informações prestadas pelos pais não iam ao encontro das necessidades das adolescentes, sendo que muitas informações necessárias à saúde sexual das jovens não eram discutidas. Tucker (1989) observou uma situação semelhante em um estudo com três gerações (filha, mãe e avó) de 53 famílias negras americanas. O autor constatou que muitas informações necessárias à saúde sexual da adolescente são negligenciados nas conversas sobre sexualidade, embora algumas mães forneçam extensa quantidade de informação às filhas sobre ciclo menstrual e conseqüências de uma vida sexual ativa. Raramente são discutidas questões referentes à anatomia, ao ato sexual, aos métodos contraceptivos disponíveis ou utilização adequada dos mesmos.

Observou-se que alguns pais, como no estudo de HockenberryEaton, Richman, Dilorio, Rivero e Maibach (1996), encontravam-se despreparados para oferecer informações, ou mesmo reforçar as informações provindas de outras fontes sobre sexualidade e contracepção. Algumas informações sobre métodos contraceptivos transmitidas foram incorretas ou desqualificavam métodos contraceptivos. Nesse sentido, percebeu-se que, na maioria das vezes, a informação prestada não tinha o intuito de uma aplicação prática, era apenas uma situação hipotética distante da realidade. Os pais podiam prestar informações às filhas somente para mantê-las informadas ou porque consideravam isso quase uma obrigação moral, decor- 
rente da própria experiência e das campanhas presentes na mídia. $\mathrm{Na}$ concepção desses pais, as informações seriam fornecidas gradualmente até o momento em que as filhas estivessem maduras o suficiente para assumirem uma vida sexual ativa, como se o fluxo da informação transmitida ditasse o ritmo da maturidade para o ato sexual. A regra desses pais se constituía em informar para impedir ou postergar a atividade sexual das filhas. A informação não foi utilizada com o objetivo de orientar ou capacitar a filha para uma vida sexual segura.

Além disso, alguns pais temiam que, ao fornecer informações sobre contraceptivos, pudessem ser interpretados como incentivando as filhas para a prática sexual. De fato, Jaccard e Duttis (1993) observaram que jovens que recebiam informação de suas mães sobre formas de prevenção podiam iniciar suas vidas sexuais mais precocemente. Contudo, tinham uma probabilidade três vezes maior de utilizar algum método contraceptivo adequadamente do que aquelas jovens que não recebiam nenhuma informação.

As mães e pais entrevistados tinham sérias dúvidas do que falar e do quanto falar às filhas sobre sexualidade e contracepção. Na verdade, esses pais possuíam uma idealização sobre o poder da informação (conteúdo) e das formas de implementação de um diálogo sobre sexualidade. Eles acreditavam que prestar informação, através de conselhos de alerta ou indicação de métodos contraceptivos, seria suficiente para orientar as jovens, seja para postergar a iniciação de suas vidas sexuais ativas, seja para iniciá-la de forma segura. A idealização decorria da crença de que eles (as mães e os pais) haviam avançado bastante em relação a seus próprios pais, no diálogo sobre sexualidade com filhos e filhas. Aliás, eles percebem-se como mais democratas e permissivos do que seus pais. Lembre-se que esses pais vivenciaram suas sexualidades com restrições e dúvidas, e sem muita informação. Em contraste, a informação que esteve ausente na adolescência, agora é percebida como tendo poderes de transformar a sexualidade. Poderia melhorar a experiência sexual das filhas, aliviaria dúvidas e angústias, e promoveria a prática sexual segura.

A conjunção da obrigatoriedade do diálogo, da negação do autoritarismo dos pais e da valorização da realização individual faz 
com que os pais procurem compartilhar mais as experiências com as filhas, estabelecendo uma relação de proximidade e amizade. Contudo, a relação de amizade idealizada parece utópica para a fase de desenvolvimento psicológico da adolescente, especialmente no que se refere à esfera sexual. Em certa medida, os pais concebem uma relação de diálogo e amizade estabelecida entre "iguais". Nessa nova forma de interação, os pais procuram não realizar proibições diretas e confiam na capacidade de antecipação de consequiências dos atos sexuais das adolescentes. A regulação desta crença estaria na confiança mútua que se estabeleceria entre pais e filhas. Na verdade, alguns pais têm a crença de que a jovem compartilhará sua iniciação sexual com eles ou deixarão a atividade sexual para mais tarde. Essas duas premissas estão presentes em suas orientações sobre sexualidade e são consideradas como aceitas pelas filhas, tanto que eles se questionam, ou se surpreendem quando a jovem não lhes comunica o início de sua vida sexual. Por outro lado, a relação de amizade e intimidade com a filha não tem uma fronteira clara. Ao mesmo tempo em que estimulam e se colocam no papel de amigos dos filhos, alguns pais não aceitam compartilhar determinadas experiências, especialmente as sexuais.

Essa ambigüidade dos pais quanto ao seu papel na orientação dos filhos, aliada às características da adolescência torna difícil uma comunicação efetiva sobre sexualidade e contracepção. Vemos que as filhas se encontram em um período confuso no qual necessitam de um modelo para orientarem seus comportamentos (Dias, Oliveira \& Gomes, 1997). O estabelecimento de normas claras é importante para a construção desse modelo. A autoridade parental é necessária, nem que seja para ser contrariada. É ela que possibilita ao jovem a construção de sua identidade (Levisky, 1995).

O ingresso dos filhos na adolescência é um período crítico também para os pais (Levisky, 1995). Eles estão da mesma forma experienciando uma série de redifinições existenciais que trarão repercussões em suas identidades. O comportamento do filho, além de questionar suas experiências e valores atuais, questiona suas próprias experiências e conflitos vivenciados em suas adolescências. Muitas vezes, os pais não conseguem colocar seus pontos de vista com 
clareza e autenticidade pois as questões dos filhos estão mobilizando seus próprios conflitos conscientes e inconscientes. Vimos que as próprias questões dos pais não resolvidas em relação à sexualidade emergem em seus diálogos com as filhas. Eles reexperienciam suas dúvidas e angústias adolescentes frente à própria sexualidade em suas conversas com as filhas. Talvez a posição de amigo(a) da filha, além de diminuir suas ansiedades frente à emergência da sexualidade dos filhos, permite a reelaboração da angústia da falta de informação e diálogo sobre sexualidade que experienciaram em sua juventude.

Os pais não percebem que sua aparente abertura também possui um caráter regulador e repressor da sexualidade, tal como as conversas proibitivas que seus pais mantinham com eles à época de sua adolescência. $\mathrm{O}$ controle da sexualidade atualmente é realizado de maneira mais sutil; ao invés de técnicas repressivas diretas, apela-se para o constante diálogo cotidiano. A sexualidade nessas famílias pode ser discutida a qualquer momento. Observa-se, neste caso, a substituição de um modelo repressivo de regulação da sexualidade por um outro modelo, em que - em contraste à repressão - incentiva-se o falar sobre a sexualidade como uma forma de controlar a mesma.

\section{Considerações finais}

O presente estudo se propôs a compreender os padrões de comunicação estabelecidos no ambiente familiar sobre sexualidade e contracepção a partir da perspectiva de pais de adolescentes gestantes. Alguns aspectos se destacaram na análise das entrevistas: 1) a experiência sexual dos pais é re-significada a partir de suas percepções das vivências das filhas; 2) a experiência comunicativa dos pais vivenciada na adolescência serve como um modelo negativo para seu diálogo com os filhos; 3 ) as transformações nos valores familiares estão influenciando na comunicação sobre sexualidade com as jovens; e 4) a identificação dos pais com os novos valores, associada à negação da própria experiência comunicativa vivida na adolescência, gera ambigüidades que estão presentes na comunicação sobre sexualidade. 
Observou-se que os pais conseguiam perceber adequadamente o que acontecia com as filhas em termos de suas sexualidades, contudo não conseguiam oferecer orientações sexuais efetivas. As suas orientações falhavam devido a diversos motivos: 1) estimativas equivocadas acerca do conhecimento das filhas sobre métodos contraceptivos; 2) tentativas de postergar a iniciação sexual das jovens; e 3) sentimentos de inaptidão para falar tanto sobre sexualidade como sobre métodos contraceptivos com as filhas.

Ressalte-se, contudo, que os resultados aqui apresentados se apoiam na análise de um número restrito de casos que constituíram a amostra desta pesquisa. Nesse sentido, novos estudos, com amostras de características sócio-econômico-culturais diferenciadas precisam ser realizados. Cabe lembrar, ainda, que esta pesquisa constitui-se numa introdução ao estudo da comunicação sobre sexualidade e contracepção no ambiente familiar. Diversos aspectos ligados à experiência da gestação na adolescência não foram aqui abordados e merecem destaque em futuras pesquisas, tais como a gestação como repetição da história familiar e a influência da estrutura familiar sobre o desenvolvimento da sexualidade das jovens e sua relação com o uso de contraceptivos. Também faz-se necessária uma investigação mais aprofundada sobre a relação existente entre a sexualidade dos próprios pais e o tipo de comunicação que estabelecem com filhas e filhos, aspecto que revelou-se importante, mas que não foi explorado em detalhe neste estudo.

\section{Referências}

Agostini, S. M. M., Luz, A. M. H., Santos, E. S., \& Mendes, S. M. A. (1988). Adolescência: informação sobre anticoncepção. Revista Gaúcha de Enfermagem, 9(1), 23-28.

Almeida, A. (1987). Maternidade: um destino inevitável. São Paulo: E.P.U.

Barnett, J. K., Papini, D. R., \& Gbur, E. (1991). Familial correlates of sexually active preganant and nonpregnant adolescents. Adolescence, 26(102), 457-472.

Benincá, C. R. S. (1994). Permutas intergeracionais na família: convergências e divergências no comportamento e nos valores. 
Dissertação de mestrado não publicada, Universidade Federal do Rio Grande do Sul, Porto Alegre.

Blos, P. (1994). Adolescência: uma interpretação psicanalítica (W. Dutra, Trad.). São Paulo: Martins Fontes. (Originalmente publicado em inglês, 1962)

Bueno, J. G. R., Neme, R. M., Neme, B., Aldrighi, J. M., Cassiani, A. G., \& Vera, S. (1996). Conhecimento dos métodos anticoncepcionais entre adolescentes do segundo grau de uma cidade de São Paulo. Jornal Brasileiro de Ginecologia, 106(5), 149-153.

Dias, A. C. G., Oliveira, V. Z., \& Gomes, W. B. (1997). A experiência de ser gestante adolescente. Revista de Ginecologia \& Obstetrícia, 8(3), 161-167.

Figueira, S. A. (1991). O "moderno" e o "arcaico" na nova família brasileira: notas sobre a dimensão invisível da mudança social. Em S. A. Figueira (Org.), Nos bastidores da psicanálise (pp.1130). Rio de Janeiro: Imago.

Fisher, R. B. (1996). Adolescência em discurso: mídia e produção de subjetividade. Tese de doutorado não publicada, Universidade Federal do Rio Grande do Sul, Porto Alegre.

Fleury, D. (1995). Gravidez na adolescência: difícil enfrentar essa barra. Revista Crescer, 18, 18-22.

Giorgi, A. (1975). An application of phenomenological method in psychology. In A. Giorgi, C. Fisher \& E. Murray (Orgs.), Duquesne studies in phenomenological psychology, Volume II (pp. 82-103). Pittisburg: Duquesne University Press.

Gomes, W. B. (1987). As aplicações sociais da pesquisa qualitativa. Psicologia: Reflexão \& Crítica, 2, 32-12.

Gomes, W. B. (1997). A entrevista e o estudo da experiência consciente. Psicologia USP, 8(2), 319-344.

Gomes, W. B. (Org.). (1998). Fenomenologia e pesquisa em psicologia. Porto Alegre: Editora da UFRGS.

Hockenberry-Eaton, M., Richman, M.J., DiLorio, C., Rivero, T., \& Maibach, E. (1996). Mother and adolescent knowledge of sexual development: the effects of gender, age, and sexual experience. Adolescence, 31, 35-47.

Jaccard, J., \& Duttis, P. (1993). Parent-adolescent communication about premarital pregnancy. Families in Society, 74(6), 329-343.

Lanigan, R. L. (1988). Phenomenology of communicology. MerleauPonty thematics in comunicology and semiology. Pittsburgh: Duquesne University Press.

Lanigan, R. L. (1992). The human science of communicology. Pittsburg: Duquesne University Press. 
Levisky, D. L. (1995). Adolescência: reflexões psicanalíticas. Porto Alegre: Artes Médicas.

Liskin, L., Kak, N., Rutledge, A. H., Smit, L. C., \& Stewart, L. (1987). A juventude na década de 1980: problemas sociais e de saúde. Population Reports, Série M(9), 1-44. (The Johns Hopkins University, Baltimore, Maryland. Edição americana: nov/dez, 1985).

Maia Filho, N. L., Mathias, L., Tedesco, R. P., Cesareo, M. D., Herculano, M. A. \& Porta, R. M. (1994). Gravidez entre adolescente precoces: um evitável problema social. Jornal Brasileiro de Ginecologia, 104(10), 363-367.

Marcelli, M., \& Braconnier, A. (1989). Manual de psicopatologia da adolescente. Porto Alegre: Artes Médicas.

Merleau-Ponty, M. (1994). Fenomenologia da percepção (C. A. R. Moura, Trad.). São Paulo: Martins Fontes. (Originalmente publicado em francês, 1945)

Monteiro, D. L. M., \& Cunha, A. A. (1994). Avaliação da freqüência da gravidez na adolescência. Jornal Brasileiro de Ginecologia, 104(1-2), 23-25.

Nicolaci-da-Costa, A. M. (1988). O processo de modernização da sociedade e seus efeitos sobre a família contemporânea. Anais da $18^{a}$ Reunião Anual da Sociedade de Psicologia de Ribeirão Preto, Brasil, 101-107.

Rodrigues, A. P., Souza, M. C. B., Brasil, R. M. C., \& Carakushansky, G. (1993). Perfil de gestantes adolescentes de um serviço prénatal público do Rio de Janeiro. Revista Brasileira de Ginecologia e Obstetrícia, 5, 223-238.

Silva, J. L. P., Sarmento, R. C., Landerer, C., \& Faundes, A. (1980). Gravidez na adolescência I: conduta frente à anticoncepção e ao sexo. Jornal Brasileiro de Ginecologia, 90(6), 283-287.

Tucker, S. K. (1989). Adolescent patterns of communication about sexuality related topics. Adolescence, 24 (94), 270-278.

Zagury, T. (1991). Sem padecer no paraíso - em defesa dos pais ou sobre a tirania dos filhos. Rio de Janeiro: Record.

Wiley, N. (1996). O self semiótico (L. P. Rouanet, Trad.). São Paulo: Loyola. (Originalmente publicado em inglês, 1994). 
104 A. C. G. Dias e W. B. Gomes

Ana Cristina Garcia Dias é mestre em Psicologia pela Universidade Federal do Rio Grande do Sul e doutoranda em Psicologia Psicologia Escolar na Universidade de São Paulo.

E-mail: anadias@vortex.ufrgs.br. William B. Gomes, doutor, é professor do Instituto de Psicologia da Universidade Federal do Rio Grande do Sul. Endereço para correspondência: Instituto de Psicologia - UFRGS, Rua Ramiro Barcelos 2600/119, Porto Alegre, RS, CEP 90035.003. Tel. (051) 3165115; 3165246, 3309507. Fax (051) 3304797.

E-mail: gomesw@vortex.ufrgs.br.
Sobre os autores 


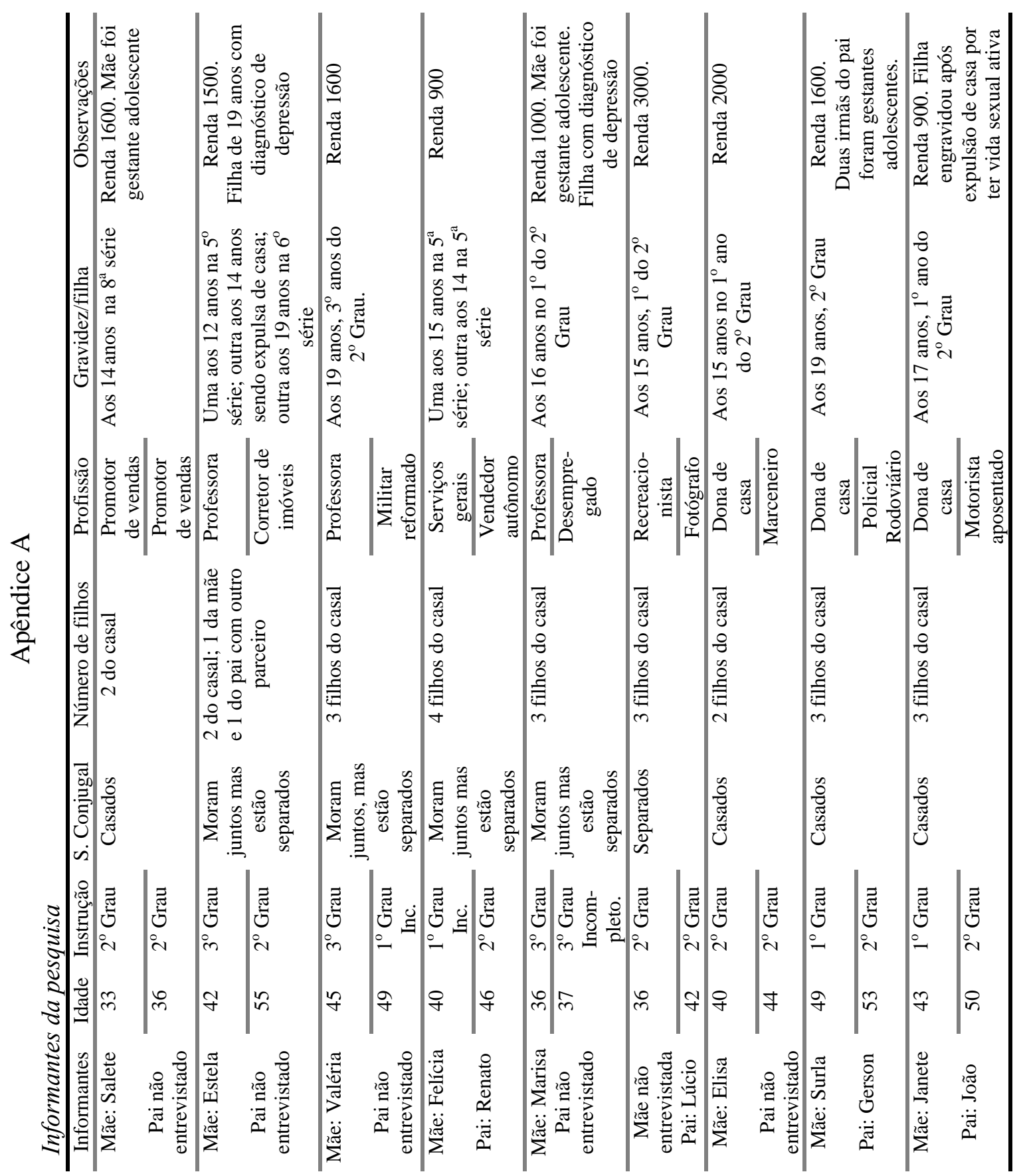




\section{Protocolo de Entrevista}

\section{Apêndice B}

Apresentação: Eu estou fazendo uma entrevista com adolescentes gestantes e seus pais para conhecer um pouco mais como está sendo a gravidez. Eu quero conhecer mais sobre essa situação para poder auxiliar outras jovens que passarão por essa situação. A tua experiência é muito importante, por isso eu gostaria de conversar contigo. Tu aceitas?

$\underline{\text { Roteiro: }}$

1. Como está sendo para você (s) a gravidez da sua filha ? (investigar sentimentos e percepções)

2. Como está sendo para os demais membros da família ?

3. Como ficou sabendo da gravidez ? (investigar o momento e os sentimentos)

4. Como a filha está vivenciando a gestação ?

5. Quais foram as mudanças ocorridas na vida familiar devido a gestação ?

6. Como foi a reação do pai da criança ?

7. Que coisas eram mais fáceis de conversar com a filha?

8. Que coisas eram mais difíceis de vocês conversaram?

9. O que gerava essa dificuldade nas conversas?

10. Que informações você acha que a tua filha possuía sobre métodos contraceptivos?

11. Como ela obteve essas informações?

12. Como foi a vivência da primeira menstruação da filha? E a sua (mãe) ?

13. Que tipo de informação você recebeu na adolescência?

14. Como era vivida a sexualidade na tua época?

15. Como tu acha que a sexualidade é vivida hoje? (investigar semelhanças e diferenças)

16. Há ou houve outros casos de gestação na adolescência na família?

17. Coleta de dados demográficos que não tenham aparecido na entrevista. (idade/ profissão/ composição familiar/ escolaridade/ renda familiar)

Finalização: Bom, era isso que eu queria conversar contigo. Alguma coisa mais que queira falar que acha importante e que poderia auxiliar outras jovens a passarem por essa experiência? Muito obrigada pela colaboração. 